\title{
As pesquisas do grupo ALTER-LAEL para a análise do trabalho educacional ${ }^{1}$
}

\author{
Anna Rachel Machado ${ }^{\mathrm{I}}$ e Eliane Gouvêa Lousada ${ }^{\mathrm{II}}$ \\ I Programa de Pós-Graduação em Linguística Aplicada e Estudos da Linguagem, \\ Pontifícia Universidade Católica de São Paulo (São Paulo, SP) \\ ${ }^{\text {II }}$ Departamento de Letras Modernas, Faculdade de Filosofia, Letras e Ciências Humanas, \\ Universidade de São Paulo (São Paulo, SP)
}

\begin{abstract}
Este artigo tem por objetivo apresentar as pesquisas desenvolvidas no grupo ALTER-CNPq (LAEL - PUC-SP), destacando nossas contribuições a partir do Interacionismo Sociodiscursivo, da clínica da atividade e da ergonomia da atividade dos profissionais da educação, visando à construção de uma proposta nossa de análise das situações de trabalho educacional, a partir de alguns aspectos dessas teorias e de teorias coerentes entre si. Para tanto, traçaremos um breve histórico da evolução de nosso grupo de pesquisa e suas relações com as linhas teóricas já mencionadas; apresentaremos os pressupostos teóricos gerais em que nos apoiamos, assim como os autores que nos servem de base; exporemos nossos procedimentos de análise e os resultados que temos obtido; e, finalmente, discutiremos as contribuições de nosso trabalho, bem como as dificuldades que encontramos.
\end{abstract}

Palavras-chave: Trabalho educacional, Clínica da atividade, Ergonomia da atividade, Interacionismo sociodiscursivo.

The research of ALTER-LAEL group to the analysis of educational work

This paper aims at presenting the research that has been carried out by ALTER-LAEL Group, highlighting its contribution to the field of educational work based on Sociodiscursive Interactionism and on clinic of activity, in order to build a model of educational work analysis. Firstly, we will present a brief history of the group evolution and its relations with the theoretical fields already mentioned; after that, we will explain the main concepts and the theoretical framework; then we will show the analysis procedures as well as the results obtained; finally, there is a discussion on the contributions and difficulties of the research.

Keywords: Educational work, Clinic of activity, Activity ergonomics, Sociodiscursive interactionism.

\section{Introdução}

$E^{s e n}$ ste artigo tem por objetivo apresentar as pesquisas desenvolvidas no grupo de pesquisa denominado Análise de Linguagem, Trabalho Educacional e suas Relações do Programa de Estudos Pós-Graduados em Linguística Aplicada e Estudos da Linguagem da Pontifícia Universidade Católica de São Paulo (ALTER-LAEL), destacando nossas contribuições a partir do interacionismo sociodiscursivo (Bronckart, 1999), da clínica da atividade (Clot, 1999/2006) e da ergonomia da atividade (Amigues, 2004; Saujat, 2002, 2004), visando à construção de uma proposta nossa de análise das situações de trabalho educacional, a partir de alguns aspectos dessas teorias e de teorias coerentes entre si, com todas as dificuldades que isso representa.

A formação do grupo ALTER ocorreu no início dos anos 2000, embora tenhamos estabelecido, desde o começo dos anos 1990, relações com o grupo de Genebra (Bronckart e outros pesquisadores), o que consolidou a teoria do interacionismo sociodiscursivo (ISD) como

1 Este artigo retoma nossa apresentação no I Colóquio de Clínica da Atividade, em outubro de 2010, na Universidade Federal de São João Del-Rei, Brasil. No entanto, ele está sendo publicado postumamente, pois a Profa. Dra. Anna Rachel Machado faleceu em maio de 2012. Nesta publicação, reiteramos nossos agradecimentos e homenagem à pesquisadora ímpar que foi Anna Rachel. 
base nuclear de nossos estudos. Essas relações, bem como a filiação ao ISD, estão na origem de vários cursos, dispositivos de formação de professores e publicações nacionais e internacionais.

Nosso interesse pela análise e compreensão das situações de trabalho educacional data da metade dos anos 1990, a partir das relações com a Université d'Aix-en-Provence (sobretudo com Daniel Faïta) e a PUC-SP, celebradas por meio de um acordo que reuniu vários professores pesquisadores. ${ }^{2}$ Essas relações resultaram em algumas publicações e se mantêm pelo acordo ${ }^{3}$ assinado em 2010/2011, por intermédio da Agence Universitaire de la Francophonie (AUF). No início dos anos 2000, nosso interesse pelas questões ligadas ao trabalho educacional se intensificou, em razão do contato com a obra de Yves Clot, ${ }^{4}$ que culminou com sua primeira vinda ao Brasil e com o início de um contato profundo e duradouro. ${ }^{5}$

Os contextos das diferentes pesquisas que constituem o projeto maior de nosso grupo é o da instituição educacional em geral, envolvendo diferentes instituições públicas e privadas de ensino, em diferentes níveis. A coleta/produção e a seleção dos dados partem de uma categorização inicialmente desenvolvida pelo Groupe Langage, Action et Formation (Groupe LAF, 2001), da Universidade de Genebra, apoiando-se em, assim como desenvolvendo, conceitos da ergonomia da atividade e da psicologia do trabalho, o que nos permite constituir o corpus com os seguintes subconjuntos de textos produzidos sobre e no trabalho educacional: textos prescritivos, textos planificadores; textos produzidos durante a realização do trabalho e textos (auto)descritivos e/ou (auto)avaliativos. Os instrumentos de coleta e ou produção de dados têm sido diversificados, incluindo-se o levantamento desses textos - orais, escritos e digitais - nas instituições envolvidas, por meio de diversos procedimentos: entrevistas, gravações em áudio e vídeo, autoconfrontação simples e cruzada, coleta de registros digitais etc.

\section{Metodologia}

O método de análise toma por base o que foi inicialmente desenvolvido na Universidade de Genebra, pelo grupo LAF, recentemente revisto em razão das próprias pesquisas por nós realizadas (Bronckart \& Machado, 2003; Machado \& Bronckart, 2005, 2009). Além disso, recorremos a conceitos e categorias de outros autores e de outras disciplinas, quando necessário, para a análise das características do contexto de produção sócio-histórico mais amplo e mais restrito, das características mais globais e das mais especificamente enunciativo-discursivas dos textos/discursos e, sobretudo, para a interpretação das análises.

O aprofundamento dos estudos tem nos permitido tanto o avanço teórico quanto o metodológico necessários para o desenvolvimento de nossas pesquisas. Do ponto de vista teórico, nosso esforço se concentrou, inicialmente, na clarificação dos conceitos centrais utilizados, tais como trabalho, atividade e ação (linguageiras e/ou discursivas e não linguageiras), tanto na ótica da psicologia do trabalho e da ergonomia da atividade, quanto na do interacionismo sociodiscursivo. Além disso, buscamos levantar pesquisas que já tenham

\footnotetext{
2 Entre eles, as Professoras Doutoras Cecília Perez de Souza-e-Silva, Beth Brait e Anna Rachel Machado.

3 Fazem parte desse acordo, além da Université de Provence e da PUC-SP, a Universidade de São Paulo, a Universidade São Francisco e a Universidade Estadual do Ceará.

4 Trata-se da obra A função psicológica do trabalho (2006), que, ao ser adotada para estudo em um seminário de pesquisa da Professora Doutora Anna Rachel Machado no LAEL-PUC-SP em 2002, a levou a contatar Yves Clot para que viesse ao Brasil, estabelecendo acordos e intercâmbios entre o CNAM e a PUC-SP. A vinda de Yves Clot ao Brasil contribuiu para reforçar o interesse pelos estudos sobre o trabalho na PUC-SP, somando-se ao interesse já despertado pelas relações estabelecidas com Daniel Faïta, que já havia trabalhado com Yves Clot em inúmeras ocasiões.

5 Hoje, temos acordos institucionais com todos os grupos de pesquisa citados, tendo estabelecido intercâmbio entre pesquisadores que vêm para o Brasil e alunos que vão para a França e para a Suíça, para ali fazerem uma parte de seu doutoramento.
} 
enfocado a atividade educacional como trabalho e pesquisas que tenham utilizado instrumental oriundo das ciências do discurso e do texto para a análise de textos produzidos nas e sobre as situações de trabalho.

Dado, entretanto, que os pesquisadores das disciplinas centrais que atravessam nossos projetos têm um forte apoio no pensamento marxista, que se reflete no pensamento de Vygotsky (1930/2003, 1934/2001), de Voloshinov (1981) e de Bakhtin (1952/1953/2000), que são também autores fundamentais para os pesquisadores com os quais trabalhamos, começamos por explorar o pensamento de Marx (que não desenvolveremos neste artigo, pois foge a nossos objetivos), discutindo alguns dos problemas que temos na sociedade contemporânea, tanto em relação ao trabalho em geral, quanto ao trabalho educacional em particular, para, a seguir, apresentar os principais aportes das teorias em que nos baseamos e que desenvolvemos com o intuito de contribuir para o enfrentamento desses problemas.

Assim, em relação à situação do trabalho educacional na sociedade contemporânea, consideramos que nossa preocupação em estudar as relações entre trabalho e educação se encontra diretamente relacionada a questões sobre o trabalho em geral, já colocadas no final do século XX. Desse modo, ao lado de Noronha (1996), admitimos que as interdeterminações entre educação, trabalho e saúde devem nos levar a refletir sobre as tendências das políticas econômicas, sociais e educacionais predominantes no Brasil nas últimas décadas, que são estreitamente relacionadas a reflexos do novo padrão econômico instaurado.

De acordo com nossa visão, consideramos que, não só no Brasil, mas em inúmeros países:

O mal-estar docente, a crise de identidade profissional dos professores têm sido discutidos como um fenômeno internacional desde os anos 1980 (Esteves, 1999), gerando-se daí uma situação de estresse e de problemas de saúde [...]. Especificamente no Brasil, os múltiplos papéis que os professores desempenham, o excesso de alunos nas classes, a pouca motivação dos alunos para o ensino escolar, os baixos salários, a multiplicação das horas de trabalho e até mesmo a violência física a que estão expostos os professores, criam uma situação de trabalho extremamente difícil (Machado \& Magalhães, 2002, p. 140).

Ao mesmo tempo, os professores se veem conclamados pelas instituições oficiais a assumir novos padrões de comportamento e a desenvolver novas "competências", ${ }^{6}$ sem que, de fato, lhes sejam dadas condições para tanto. Tudo isso, sem dúvida, posiciona-os ao lado dos outros trabalhadores, em seu sentimento de instabilidade e de quebra de suportes para o exercício de sua atividade profissional.

Sendo assim, consideramos que a problemática geral que motivou o desenvolvimento das pesquisas está ligada ao fato de que havia (e há) poucas pesquisas sobre o trabalho docente (compreendido no sentido de uma noção teórica, segundo os aportes da ergonomia da atividade dos profissionais da educação e da clínica da atividade) e à nossa tomada de posição contra o discurso institucional e as pesquisas que constroem a imagem do professor como "alguém a quem falta sempre alguma coisa" e, finalmente, à crença, ao lado de outros pesquisadores que estudam o trabalho, de que o ensino como trabalho é um enigma.

Porém, como deixamos entrever, no interior do grupo ALTER-LAEL, não desenvolvemos apenas a clínica da atividade ou a ergonomia da atividade, nem exatamente o interacionismo sociodiscursivo. Logo, a pergunta que nos colocamos e a que gostaríamos de responder neste artigo é: quais pesquisas fazemos no grupo ALTER-LAEL?

É para essa questão que se voltam as próximas seções, divididas em: objetivos das pesquisas e quadro teórico-metodológico, procedimentos de análise de dados, resultados ao

6 Uma crítica ao conceito de competências, compreendido como algo vago e pouco definido que invadiu o mundo do trabalho e também da educação, pode ser lida em Dolz e Ollagnier (2004). 
longo de três momentos de nossos estudos e, finalmente, as considerações finais, ressaltando as dificuldades que encontramos e os aportes que trazemos.

\section{Objetivos das pesquisas do grupo ALTER-LAEL e quadro teórico-metodológico adotado}

Tendo em vista a problemática geral que acabamos de expor, propomo-nos, como objetivos gerais do grupo, a verificar a apropriação e a adequação de utilizar conceitos, categorias e procedimentos de outras disciplinas e das três linhas teóricas já citadas para a análise das diferentes situações do trabalho docente e, também, a desenvolver estudos sobre as práticas linguageiras no e sobre o trabalho docente, a fim de contribuir para sua compreensão, em um primeiro momento, e, a partir dessa compreensão, em um segundo momento, construir propostas de intervenção em formação inicial e contínua. Esses objetivos decorrem, e simultaneamente determinam, do quadro teórico-metodológico que adotamos em nossas pesquisas e que apresentaremos a seguir.

Na busca de colaborar para a superação dos graves problemas que cercam o trabalhador da educação, mas também de outras áreas, a psicologia do trabalho tem trazido importantes aportes, principalmente na chamada clínica da atividade, desenvolvida em especial no Conservatoire National des Arts et Métiers de Paris, França (CNAM) e explicitada em Clot (1999/2006). Nessa obra, o autor não chega a definir de forma rigorosa o termo "trabalho", mas já o considera como uma forma de atividade, entre outras, com uma função psicológica central, o que faz com que o autor busque estudar as implicações das atividades de trabalho para o desenvolvimento das funções psíquicas tipicamente humanas. Assim, o objeto de seu estudo é esse desenvolvimento, sua história e seus impedimentos, desenvolvimento esse que, de acordo com os postulados metodológicos da linha vygotskyana, só pode ser apreendido e definido no seu desenrolar histórico e não como sendo unidirecional e predeterminado do exterior da situação de trabalho.

Contribuição importante ainda de Clot (1999/2006) é a ideia de que, em muitas situações de trabalho, os trabalhadores são submetidos a uma verdadeira "amputação de seu poder de agir", de grande parte de suas capacidades, com o silenciamento e o ocultamento de uma série de atividades que poderiam desenvolver. Dessa forma, o autor sustenta uma concepção da atividade humana que implica uma concepção dos homens como seres irredutíveis às formas predeterminadas e como sendo potencialmente criadores do novo.

Ainda retomando a já consensual divisão da ergonomia entre o "trabalho prescrito" (as prescrições que as instituições/empresas prescrevem aos trabalhadores para a realização de tarefas específicas) e o "trabalho realizado"7 Clot (1999/2006) considera que as prescrições não devem ser encaradas negativamente, mas como uma parte constitutiva, pois não haveria trabalho possível sem um mínimo de prefiguração, isto é, de prescrições: "Sem lei comum a fazer viver, o trabalho deixa cada um de nós diante de si mesmo, apenas"8 (Clot, 1999, p. 9).

Além disso, partindo das duas dimensões do trabalho estabelecidas pela ergonomia, Clot (1999/2006) introduz uma terceira dimensão, a do real da atividade. Assim, para ele, teríamos:

-Trabalho prescrito: anterior ao trabalho propriamente dito, que diz o que o trabalhador deve fazer para a realização das tarefas;

7 Trabalho real, nos termos da Ergonomia clássica.

8 Tradução nossa. 
-Trabalho realizado: o trabalho que se "vê" efetivamente, que é feito;

- Real da atividade: inclui o trabalho que é realizado, mas vai além dele, incorporando também o que Clot (1999/2006) chama de "atividades contrariadas" do trabalhador, isto é, todas as atividades que ele poderia desenvolver, mas que são suspensas ou impedidas por diferentes fatores próprios de cada situação de trabalho.

Já em relação aos aportes da ergonomia da atividade e, mais especificamente, do grupo ERGAPE (Ergonomie de l'Activité des Professionnels de l'Education) ${ }^{9}$, sediado no Institut de Formation de Maîtres (IUFM) de Marselha, em primeiro lugar, cumpre dizer que as ideias desse grupo são muito próximas aos do grupo da clínica da atividade, mas que suas pesquisas incidem especificamente sobre a questão do trabalho educacional, sobretudo para a formação inicial e contínua de professores. Evidentemente, os aportes daí derivados têm sido de grande importância para nossas próprias pesquisas, merecendo destaque a definição do trabalho educacional proposta por Amigues (2004), a partir da qual elaboramos nossa própria definição, provisória, de trabalho educacional, que reproduzimos a seguir. ${ }^{10}$ Consideramos que o trabalho do professor é constituído de múltiplas atividades, desenvolvidas em diferentes situações que precisam ser investigadas, pois se inter-relacionam. Sendo assim, podemos dizer que, em relação ao trabalho desenvolvido em sala de aula, o professor mobiliza seu ser integral, em suas múltiplas dimensões (físicas, cognitivas, linguageiras, afetivas etc.), com o objetivo de criar um ambiente propício à aprendizagem de determinados conteúdos pelos alunos e ao desenvolvimento de capacidades a eles relacionadas, direta ou indiretamente. Além disso, a realização de seu trabalho é desenvolvida em interação permanente com outros actantes (com os alunos, principalmente, mas também com "outros" não presentes fisicamente na situação). Trata-se de uma atividade instrumentada, no sentido de que o professor, para realizá-la, utiliza instrumentos materiais ou simbólicos, oriundos da apropriação, por si e para si, de artefatos disponibilizados pelo seu meio social. Nesse sentido, sua atividade pode ser altamente criativa, dado que o professor recria esses artefatos de acordo com as diferentes situações, necessidades e capacidades. Finalmente, podemos dizer que sua atividade é orientada por diferentes prescrições institucionais de diferentes níveis (PCNs, por exemplo, no caso do ensino de gêneros textuais) e por modelos do agir, historicamente construídos pelo coletivo de trabalho. Essas prescrições, de modo teórico, não podem ser vistas como negativas, mas como artefatos disponibilizados para o professor e que podem facilitar o seu trabalho. Segundo apontam Saujat (2002, 2004), Faïta (2004) e Amigues (2003, 2004), elas são frequentemente objeto de reconcepção, pelos professores. Em outras palavras, o professor adapta as prescrições iniciais a seu contexto particular de ensino, reconcebendo-as, redefinindo-as.

Finalmente, quanto aos aportes do interacionismo sociodiscursivo (ISD) para nossas pesquisas, consideramos que eles se centram fundamentalmente na clarificação das relações entre atividades e ações docentes, de um lado, e de suas representações (ou (re)configurações no sentido de Ricoeur, 1983) nos e pelos textos, de outro, assim como no fornecimento de um quadro teórico-metodológico que nos possibilita detectar essas representações - ou (re)configurações - com um instrumental analítico bastante refinado e informado pelos estudos da linguagem.

Como paradigma diferenciado da psicologia, que busca uma compreensão do funcionamento e do desenvolvimento humanos, com uma abordagem transdisciplinar, o ISD propõe problemas, objetos, unidades de análise e metodologia específicos, com forte apoio nos estudos da linguagem, privilegiando, de forma acentuada, as abordagens que dão primazia ao social, como as de Saussure e Voloshinov. Para isso, toma como sua fonte de referência maior as ideias de Vygotsky, desenvolvidas no quadro da psicologia soviética e influenciadas pelas ideias

9 Parece-nos fundamental ressaltar que nos apoiamos, sobretudo, nos desdobramentos dos pressupostos teóricos de base da ergonomia, propostos pelos grupos da Ergonomia da Atividade dos profissionais da educação e da clínica da atividade.

10 Essa definição foi apresentada em outros artigos, dentre os quais, um publicado na Revista Linguagem em (Dis)curso (2010). 
de Hegel, Marx e Engels (1991). Complementarmente, o ISD faz empréstimos de conceitos de teorias da ação, reformulando-as e integrando-as, tais como a de Habermas (1987) e a de Ricoeur $(1977,1983,1990)$.

Sua característica distintiva em relação a outras vertentes interacionistas sociais está na ênfase especial que dá ao papel da linguagem no desenvolvimento psíquico humano, "como [sendo] processo de negociação e de estabelecimento de acordo sobre a atividade em que o homem está envolvido e como instrumento de avaliação da atividade" e da ação de cada um (Bronckart, 1997). Assim, as produções textuais seriam o meio pelo qual se constroem as representações sociais e racionais que permitem que os indivíduos se situem e julguem cada contribuição particular para a realização das atividades sociais.

Essa construção se faria nas atividades sociais, reguladas e mediadas por interações verbais, por um agir comunicativo, em negociações permanentes (frequentemente conflituosas) entre as avaliações do outro e a representação que o indivíduo tem de si mesmo, negociação essa que geraria a sua transformação contínua. Portanto, para nossa pesquisa, assumir esses pressupostos significa assumir que o desenvolvimento dos trabalhadores também se realizaria pelo confronto entre as representações que os textos de cada um constroem sobre o seu próprio agir ou do outro e os textos produzidos por avaliações externas.

Entretanto, a partir dessa escolha, o ISD defronta-se com um problema de ordem metodológica: como interpretar a ação e, através dela, a pessoa que age? Segundo o ISD, não podemos ter acesso direto ou indireto à ação, do ponto de vista psicológico. Dessa forma, só seria possível interpretá-la nas e através das produções verbais efetivamente realizadas, dos textos produzidos, utilizando-nos de uma metodologia compreensiva/interpretativa, inspirada na de Ricoeur $(1977,1983,1990)$, pois "é através da análise de discurso, num processo de interpretação dos textos bem instrumentada, que as ações humanas podem ser interpretadas" (Bronckart, 1997). Justifica-se, assim, a necessidade de analisarmos os textos produzidos sobre e no trabalho, pois seria essa análise que poderia nos fornecer uma melhor compreensão sobre a atividade e as ações educacionais.

De acordo com esses pressupostos, os dados coletados, selecionados e analisados em diferentes pesquisas de nosso grupo, têm sido dos seguintes tipos, produzidos em diferentes níveis de ensino:

- textos da mídia (especializada em problemas educacionais ou não), que trazem representações sobre o trabalho docente;

- textos prescritivos produzidos por diferentes instâncias governamentais ou pela direção e coordenação das escolas para os professores, antes das tarefas. Ex.: Carta introdutória do Ministro da Educação para Os Parâmetros Curriculares Nacionais;

- textos de instruções de professores para um possível substituto, antes da realização de uma tarefa; ${ }^{11}$

- textos produzidos em situação de trabalho;

- textos produzidos pelos próprios professores, após a realização de uma determinada tarefa; ${ }^{12}$

- textos produzidos por observadores do trabalho dos professores (alunos ou estagiários supervisionados).

11 São os textos de "instrução ao sósia", metodologia desenvolvida no campo das ciências do trabalho, mais especificamente por Ivar Oddone, na Fiat da Itália, na década de 1970, e usada pelos pesquisadores da clínica da atividade.

12 Esses textos podem ser relatórios de estágio, relatos de experiência vivida, diários de aula, entrevistas ou, ainda, as autoconfrontações (simples e cruzada), método criado por estudiosos da ergonomia (as chamadas "confrontações") e desenvolvido por Daniel Faïta, em colaboração com vários pesquisadores (Yves Clot, Marcos Vieira, entre outros). O método das autoconfrontações continuou a ser desenvolvido por Daniel Faïta e sua equipe, o grupo ERGAPE e também pelos pesquisadores da clínica da atividade. 
Para analisar os textos elencados acima, podemos dizer que nosso modelo de análise de dados reúne os aportes do interacionismo sociodiscursivo de Bronckart (1997), porém, renovado a partir de nossas pesquisas (Bronckart \& Machado, 2003; Machado \& Bronckart, 2005, 2009; Lousada, 2006; Mazzillo, 2006; Abreu-Tardelli, 2006; Barricelli, 2007; Bueno, 2007; Machado \& Lousada, 2010; entre outros), convoca outros autores compatíveis com esse quadro teórico, se necessário, e propõe um modelo de análise que não é estático, mas que se adapta ao conjunto de dados analisados e ao dinamismo das interações que são objeto de nossa análise. A exposição desse modelo é justamente o objeto da próxima seção.

\section{Procedimentos de análise de dados do grupo ALTER-LAEL}

Os procedimentos de entrada no texto, de sua análise e de sua interpretação para a detecção das representações (reconfigurações) do agir ${ }^{13}$ nos e pelos textos podem ser divididos em três grandes grupos, em uma abordagem predominantemente descendente-ascendente (do contexto para as unidades textuais menores e vice-versa). Assim, em um primeiro momento, sem análise do texto propriamente dito, desenvolvemos:

- estudo sobre o contexto sociointeracional mais amplo;

- levantamento de hipóteses sobre as representações iniciais do(s) enunciador(es) sobre o contexto de produção imediato;

- análise do tipo de suporte(s) em que o texto é veiculado e suas características e de suas características gerais (discursivas, visuais etc.);

- levantamento do cotexto que circunda os textos a serem analisados;

- levantamento do gênero a que o texto é especificamente relacionado.

O segundo grupo de procedimentos constitui-se em uma análise do texto propriamente dito, com base, em grande parte, no modelo de produção de textos proposto por Bronckart (1997) e revisto por Machado e Bronckart (2005, 2009), que guarda visíveis semelhanças com procedimentos habitualmente desenvolvidos por diferentes analistas de texto e/ou de discurso, como Maingueneau, (1994, 1996), Adam (2008), Kerbrat-Orecchioni (1990), Authier-Revuz (2001), consultados para o enriquecimento das análises e de acordo com as especificidades dos textos.

Esses procedimentos abrangem:

a) a detecção dos constituintes da infraestrutura textual, que são:

- o plano global de texto, que nos permite clarificar o estatuto dialógico da estrutura global do texto e a detecção inicial dos principais actantes postos em cena no texto;

- os tipos de discurso ${ }^{14}$ que constituem o texto e os valores assumidos pelas unidades dêiticas que os caracterizam;

- as sequências que constituem os tipos de discurso, interpretando o seu valor dialógico.

b) a detecção dos mecanismos centrais de textualização, abrangendo:

- mecanismos de coesão nominal e verbal;

- mecanismos de conexão.

13 Consideramos que o trabalho, educacional ou outro, é uma forma de agir.

14 Para explicações completas sobre tipos de discurso e sobre as unidades linguísticas que os caracterizam, consultar, por exemplo, Bronckart (1997). 
c) mecanismos enunciativos, abrangendo:

- detecção das vozes presentes no texto e de seus valores;

- detecção das modalizações e de seus valores.

Queremos salientar, aqui, que é de particular interesse para o levantamento dos posicionamentos do produtor (na maior parte de nossos textos, o professor), em relação a seu trabalho, o levantamento e a análise das modalizações ou das relações predicativas.

Para isso, primeiramente, distinguimos as relações predicativas diretas, em que a forma verbal não aparece precedida de um metaverbo com valor modal, aspectual ou psicológico (a relação sujeito-verbo é, portanto, "neutra" ou simplesmente assertiva) e, a seguir, as relações predicativas indiretas, em que um verbo com um desses valores está inserido entre o sujeito e o verbo. Nesse segundo caso, em função de nossos objetivos de pesquisa, classificamos os metaverbos (ou verbos auxiliares) em função de cinco valores: valor deôntico (dever, ser preciso etc.), com o que podemos detectar "determinações externas" para o agir representado; valor pragmático (querer, tentar, buscar, procurar etc.), com o que podemos detectar os "objetivos" do agir desejados por um determinado agente; valor psicológico (pensar, acreditar, considerar etc.), com o que podemos detectar os recursos ou capacidades do agente mobilizados ou não para um determinado agir; valor epistêmico (ser verdade, poder etc.), com o que podemos detectar o grau de verdade ou de certeza objetiva que o produtor atribui a seu enunciado; valor apreciativo (gostar, apreciar etc.), com o que podemos detectar a posição subjetiva de um determinado actante em relação ao predicado.

Finalmente, chegamos ao terceiro grupo de procedimentos, que se constitui na detecção das funções sintático-semânticas dos sintagmas nominais que representam os principais actantes postos em cena no e pelo texto. Esses procedimentos envolvem:

- uma reinterpretação das análises anteriores à luz de categorias de uma "semântica (ou semiologia) do agir";

- categorização semântica dos verbos e das modalizações que acompanham os principais actantes postos em cena.

Para isso, adotamos uma terminologia ad hoc, segundo a qual o termo "agir" designa qualquer ocorrência (no texto) de intervenções de seres humanos no mundo, quaisquer que elas sejam, sem maiores análises e interpretações.

Aprofundando essas análises, podemos identificar se, nos segmentos analisados, encontramos:

a) no plano motivacional:

- a explicitação de "determinações externas" para o agir, estabelecidas por um coletivo, materiais ou simbólicas;

- ou de "motivos" para o agir, interiorizados por uma pessoa particular.

b) no plano da intencionalidade:

- a explicitação de "finalidades" para o agir, de ordem do coletivo e socialmente validadas;

- ou das "intenções ou objetivos", interiorizados por uma pessoa particular.

c) No plano dos recursos para o agir:

- explicitação de "artefatos" socialmente disponibilizados para a realização do agir, quer sejam materiais, quer sejam simbólicos;

- ou "instrumentos psicológicos" já apropriados pelos actantes; 
- ou ainda as "capacidades", ou os recursos mentais ou comportamentais, atribuídas a uma pessoa particular.

A partir daí, podemos dizer se temos nos textos a representação de atividades ou de ações, pois reservamos o termo "atividade" para o agir que é posto no texto como sendo desenvolvido coletivamente, por vários actantes, motivado por razões, dirigido a determinada finalidade do coletivo, que é posto como tendo recursos para a realização desse agir. Já o termo "ação" é reservado ao agir que é posto no texto como sendo individual, movido por motivos próprios do actante, que se volta para atingir um determinado objetivo pessoal e que tem recursos e capacidades para sua realização.

Assim, em relação aos seres humanos que intervêm em um determinado agir encenado pelo e no texto, tomamos o termo "actante" para designar qualquer pessoa implicada em qualquer tipo de agir. Entretanto, consideramos que esse actante é posto como verdadeiro "ator", quando a ele são atribuídos motivos e intenções, recursos e capacidades, e que, ao contrário, ele é posto como simples "agente", quando a ele não são atribuídos esses motivos, nem intenções, nem recursos, nem capacidades.

É com os procedimentos elencados acima que já pudemos detectar diferentes representações (configurações) que se constroem nos e pelos textos a respeito do trabalho educacional, dos papéis atribuídos a seus diferentes actantes e às diferentes formas de ação ou de atividade (realizada ou impedida) que também lhe são atribuídas, sempre pela ótica do real da atividade, dos conflitos e dos impedimentos à realização do trabalho, em razão de nossos contextos de trabalho e de pesquisa.

Cabe salientar que a especificidade de nossas análises advém do fato de nos basearmos na análise enunciativa, discursiva e linguística, porém, interpretando essas análises sob a ótica d a clínica da atividade e da ergonomia da atividade. Sendo assim, parece-nos importante apontar que usar as "lentes" da clínica da atividade e da ergonomia da atividade traz uma base interpretativa mais ampla ao interacionismo sociodicursivo, constituindo o modelo de análise do grupo ALTER-LAEL.

\section{Resultados das pesquisas}

Nossas pesquisas têm revelado problemáticas que se assemelham, mesmo vindo de diferentes situações de trabalho educacional, e que podem ser listadas, muito resumidamente, como: ausência do professor na elaboração de prescrições para o trabalho educacional; prescrições muito vagas que trazem muitas exigências do professor mas não explicam efetivamente como realizar seu trabalho; sobrecarga de trabalho e dificuldade, para o professor, de tomar as rédeas de seu trabalho e de seu desenvolvimento profissional; formação de professores baseada nas teorias da didática e da educação, mas que aborda muito pouco as questões mais cotidianas do trabalho, o que cria inúmeros desafios para o jovem professor que inicia sua carreira profissional; pouca importância dada aos contextos de realização do trabalho educacional tanto na formação inicial quanto na formação contínua; entre outras.

Essas problemáticas encontradas em nossas análises refletem três grandes momentos das pesquisas do grupo ALTER-LAEL. O primeiro deles, que se iniciou com a criação do grupo, em 2002, deu origem a pesquisas que se voltaram para os textos que veiculam prescrições. A análise de textos prescritivos da escola genebrina e da educação no Brasil pertence a esse primeiro momento (Machado \& Bronckart, 2005).

Já em um segundo momento, podemos dizer que as pesquisas começaram a se voltar para os textos produzidos antes ou depois da realização da tarefa. Datam desse momento várias 
teses defendidas no LAEL - PUC-SP, como as de Abreu-Tardelli (2006), Lousada (2006), Mazzillo (2006), Bueno (2007), entre outras.

Em um terceiro momento, no qual nos encontramos atualmente, as pesquisas se voltam para propostas de formação de professores e para o encontro de soluções para os problemas no trabalho, mas construídas com os professores-trabalhadores (artefatos e instrumentos utilizados/criados). Nesse momento, os textos produzidos e analisados são relatórios de estágio, relatos de experiência vivida, diários de aula, autoconfrontações simples e cruzadas e instruções ao sósia, porém com especial atenção aos momentos de retorno ao coletivo de ambos os métodos. Quanto aos procedimentos metodológicos de análise, cabe ressaltar que temos aprofundado algumas categorias de análise, dentre as quais as "figuras de ação", propostas por Bulea (2010) e que têm nos permitido compreender a apropriação e reconfiguração do agir pelas pessoas.

Sendo assim, o grupo se volta atualmente para uma discussão sobre a formação inicial e contínua, tendo realizado várias apresentações e publicações (Machado \& Lousada, 2010; Lousada, Barricelli \& Oliveira, 2011), além de estar desenvolvendo um projeto com a Universidade de Provence e a equipe ERGAPE (Ergonomie de l'Activité des Professionnels de l'Education), financiado pela AUF e voltado exclusivamente para a formação de professores.

\section{Considerações finais}

Os resultados que mencionamos acima mostram a importância de nossas pesquisas para uma compreensão diferenciada do que é efetivamente o trabalho educacional e para propostas de formação de professores que sejam condizentes com uma visão mais humana e mais compromissada com o real desenvolvimento profissional (e pessoal) dos professores.

No entanto, parece-nos importante salientar que esses avanços e descobertas ainda são minoritários e precisam ser divulgados mais amplamente no campo da educação, em geral, no Brasil. Para tanto, é preciso enfrentar vários desafios que atravessam a vida do pesquisador brasileiro, tais como: a dificuldade de constituir uma equipe interdisciplinar e, mais do que isso, de propor modelos teóricos abertos a várias disciplinas que, muitas vezes, não dominamos plenamente e cujas relações não são aceitas por todos; a dificuldade de penetrar realmente nas escolas para poder, não apenas coletar dados, mas participar das mudanças na instituição de ensino, já que há outras linhas de formação de professores que dominam a cena educacional brasileira; dificuldades relacionadas à própria vida profissional do pesquisador brasileiro, o qual encontra vários entraves de ordem burocrática, além do excesso de trabalho. São inúmeros, enfim, os obstáculos que temos que enfrentar, de ordem teórica, metodológica, política e, até mesmo, econômica.

Apesar de tudo, consideramos que ultrapassar essas dificuldades é possível, sobretudo a partir da interação maior entre os pesquisadores de disciplinas diferentes, mas que compartilham as mesmas concepções teóricas, e da qual este volume é um exemplo.

\section{Referências}

Abreu-Tardelli, L. S. (2006). Aportes para compreender o trabalho do professor iniciante em EAD. Tese de Doutorado em Linguística Aplicada e Estudos da Linguagem, Pontifícia Universidade Católica de São Paulo, São Paulo. 
Adam, J. -M. (2008). A lingüística: introdução à análise textual dos discursos. São Paulo: Cortez.

Amigues, R. (2003). Pour une approche ergonomique de l'activité enseignante. IUFM d'Aix-Marseille. (cópia por e-mail cedida pelo autor)

Amigues, R. (2004). Trabalho do professor e trabalho de ensino. In A. R. Machado (Org.), O ensino como trabalho: uma abordagem discursiva (pp. 35-54). Londrina: Eduel.

Authier-Revuz, J. (2001) Palavras incertas: as não coincidências do dizer. Campinas: Unicamp.

Bakhtin, M. (2000/1952/53). Estética da criação verbal. São Paulo: Martins Fontes.

Barricelli, E. (2007). A reconfiguração pelos professores da proposta curricular de educação infantil. Dissertação de Mestrado em Linguística Aplicada e Estudos da Linguagem, Pontifícia Universidade Católica de São Paulo, São Paulo.

Bronckart, J.-P. (1997/1999). Atividade de linguagem, textos e discursos: por um interacionismo sócio-discursivo (Anna Rachel Machado e Péricles Cunha, trad.) São Paulo: Educ.

Bronckart, J.-P. \& Machado, A. R. (2003). En quoi et comment les "texte prescriptifs" prescrivent-ils? Analyse comparative de documents éducatifs brésiliens et genevois. In L Filliettaz \& J.-P. Bronckart (Orgs.), L'analyse des actions et des discours en situation de travail. Concepts, méthodes et applications. Louvain-laNeuve: Peeters. Collection Bibliothèque des Cahiers de l'Institut de Linguistique de Louvain.

Bueno, L. (2007). A construção de representações sobre o trabalho docente: o papel do estágio. Tese de Doutorado em Linguística Aplicada e Estudos da Linguagem, Pontifícia Universidade Católica de São Paulo, São Paulo.

Bulea, E. (2010). Linguagem e efeitos desenvolvimentais da interpretação da atividade. Campinas: Mercado de Letras.

Clot, Y. (2006). A função psicológica do trabalho. Petrópolis: Vozes. (Originalmente publicado em 1999. Título original: La fonction psychologique du travail. Paris: PUF)

Dolz, J. \& Ollagnier, E. (2004). O enigma da competência em educação. Porto Alegre: Armed.

Faïta, D. (2004). Gêneros de discurso, gêneros de atividade, análise da atividade do professor. In A. R. Machado (Org.), O ensino como trabalho: uma abordagem discursiva (pp. 53-80). Londrina: Eduel.

Groupe LAF - Langage, action, formation. (2001). Lanalyse des actions et des discours en situation de travail et leur exploitation dans les démarches de formation. Analyse du travail et formation professionnelle. Recueil de textes du Séminaire romand de 3ème cycle en Sciences de l'éducation. Genebra: Universidade de Genebra.

Habermas, J. (1987). Théorie de l'agir communicationnel (v. I e v. II). Paris: Fayard.

Kerbrat-Orecchioni, C. (1990). Les interactions verbales (v. I). Paris: Armand Colin.

Lousada, E. G. (2006). Entre o trabalho prescrito e o realizado: um espaço para a emergência do trabalho real do professor. Tese de Doutorado em Linguística Aplicada e Estudos da Linguagem, Pontifícia Universidade Católica de São Paulo, São Paulo.

Lousada, E., Barricelli, E. \& Oliveira, S. M. (2011). Gêneros textuais em foco: instrumentos para o desenvolvimento de alunos e professores. Revista de Estudos Linguísticos, São Paulo, 40 (2), 627-640.

Machado, A. R. \& Bronckart, J.-P. (2005). De que modo os textos oficiais prescrevem o trabalho do professor? Análise comparativa de documentos brasileiros e genebrinos. DELTA, Documentação de Estudos em Lingüística Teórica e Aplicada, 21 (2), 183-214.

Machado, A. R. \& Bronckart, J.-P. (2009). (Re-)configurações do trabalho do professor construídas nos e pelos textos: a perspectiva metodológica do grupo. In A. R. Machado, L. Abreu-Tardelli \& V. L. L. Cristovão (Orgs.), Linguagem e educação: o trabalho do professor em uma nova perspectiva (pp. 31-77). Campinas: Mercado de Letras.

Machado, A. R. \& Lousada, E. G. (2010). A apropriação de gêneros textuais pelo professor: em direção ao desenvolvimento pessoal e à evolução do "métier". Linguagem em (Dis)curso, 10, 619-633.

Machado, A. R. \& Magalhães, M. C. (2002). A assessoria a professores na universidade brasileira: a emergência de uma situação de trabalho a ser desvelada. In M. C. P. Souza-e-Silva \& D. Faïta (Orgs.), Linguagem e trabalho: construção de objetos de análise no Brasil e na França (pp. 139-156). São Paulo: Cortez.

Maingueneau, D. (1994). Lénonciation en linguistique française. Paris: Hachette.

Maingueneau, D. (1996). Les termes-clés de l'analyse du discours. Paris: Seuil.

Marx, K. \& Engels, F. (1845-6/1991). A ideologia alemã (Feuerbach). São Paulo: Hucitec. 
Mazzillo, T. (2006). O trabalho do professor de língua estrangeira representado e avaliado em diários de aprendizagem. Tese de Doutorado em Linguística Aplicada e Estudos da Linguagem, Pontifícia Universidade Católica de São Paulo, São Paulo.

Noronha, O. M. (1996) Educação e trabalho: algumas reflexões. TransINformação, 8 (1).

Ricoeur, P. (ed.). (1977). La sémantique de l'action. Paris: CNRS.

Ricoeur, P. (1983). Temps et récit, 1. Paris: Seuil.

Ricoeur, P. (1990). Soi-même comme un autre. Paris: Seuil.

Saujat, F. (2002). Ergonomie de l'activité enseignante et développement de l'expérience professionnelle: une approche clinique du travail du professeur. Tese de Doutorado em Ciências da Educação, Université d'Aix-Marseille, França.

Saujat, F. (2004). O trabalho do professor nas pesquisas em educação: um panorama. In A. R. Machado (Org.), O ensino como trabalho: uma abordagem discursiva (pp. 3-34). Londrina: Eduel.

Voloshinov, V. (1981). Le marxisme et la philosophie du langage. Paris: Seuil.

Vygotski, L. S. (1930/2003). A formação social da mente. São Paulo: Martins Fontes.

Vygotski, L. S. (1934/2001). A construção do pensamento e da linguagem (Paulo Bezerra, trad.). São Paulo: Martins Fontes.

\section{Endereço para correspondência}

elianelousada@uol.com.br

Recebido em: 21/08/2012

Revisado em: 28/04/2013

Aprovado em: 09/05/2013 